\title{
IMIA and its Members: On Balancing Continuity and Transition in Biomedical and Health Informatics
}

\author{
Reinhold Haux (President of IMIA 2007-2010) \\ Peter L. Reichertz Institute for Medical Informatics, University of Braunschweig - Institute of Technology \\ and Hannover Medical School, Germany
}

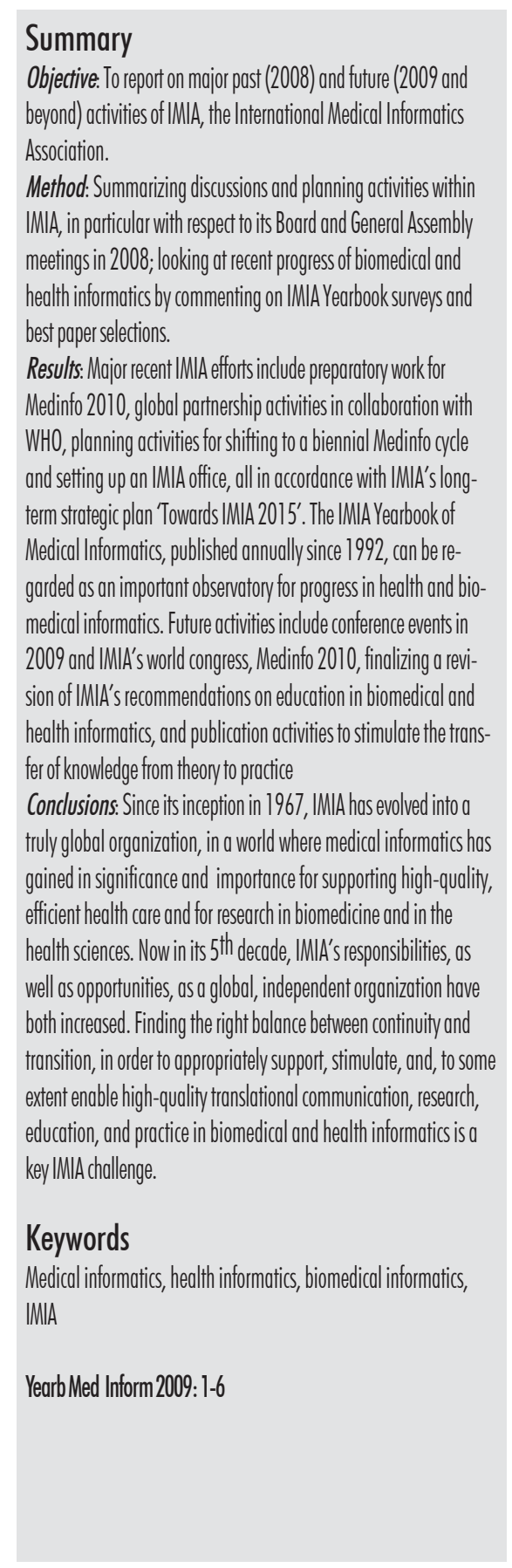

\section{Introduction}

In 2009, the current President of the International Medical Informatics Association (IMIA) presents his second report on some of IMIA's major past and future activities in this issue of the IMIA Yearbook of Medical Informatics. Previous reports during my presidency have been presented in [1], [2], and, to some extent (section 7), in [3]. The structure of this report is essentially the same as last year's [2], taking into account that some redundancy cannot be avoided. References, already given in [2], are usually not repeated, but updated ones have been added. Hence, for more references the reader is refered back to [2].

\section{About IMIA}

\subsection{IMIA's Goals and Objectives}

As indicated on IMIA's web site [4], the Association's goals and objectives include:

- the promotion of informatics in health care and biomedical research,

- the advancement of international cooperation,

- the stimulation of research, development and education, and

- the dissemination and exchange of information.

For more than 40 years, IMIA has been a bridging organization, as medical informatics is an integrative discipline. IMIA supports, stimulates, and, to some extent enables, high-quality translational communication, research, edu- cation, and practice in biomedical and health informatics. Inherent in IMIA's mission is the bringing together, from a global perspective, of scientists, researchers, vendors, consultants and suppliers in an environment of cooperation and sharing. The international membership network of National Member Societies, IMIA Regions, Corporate and Academic Institutional Members, and our Working and Special Interest Groups that constitute the 'IMIA family" is uniquely positioned to achieve these goals.

IMIA is the only organization in health and biomedical informatics which is truly international and multi-disciplinary in scope, bridging the academic, health practice, education, and health industry worlds through conferences, working group activities and publications.

\subsection{IMIA Members}

From an initial founding set of twelve national groups, IMIA has grown to a worldwide network of National Member Societies, Academic Institutions, Corporate Members, Working and Special Interest Groups, and affiliated organizations, as well as corresponding members from non-member countries.

At the end of 2008, 86 nations (53 full members and 33 corresponding members), 49 academic institutions, and 11 corporations were directly represented as members of IMIA's growing family (Table 1). In addition there are three affiliated organizations, including the World Health Organization (WHO, [5]), where IMIA has been privileged for many years to be one of 
WHO's non-governmental organizations. When one includes the members of IMIA's working groups, representative member organizations exceed 150. IMIA's national member societies, in turn, represent over 50,000 individuals.

Table 1 presents the growth of IMIA membership over the past five years. It is again noteworthy that in the last few years there has been an increasing membership in Africa, South America and the Middle East. IMIA is evolving into a truly global organization free of the constraints of political and cultural barriers.

IMIA Regions (broadly aligned with WHO's regions, see [6]), and consisting of IMIA member nations and others, actively participate in IMIA by sending a Vice President to represent their interests at the IMIA Board and General Assembly. Currently IMIA regions are APAMI, the Asia Pacific Association for Medical Informatics [7], EFMI, the European Federation for Medical Informatics [8], HELINA, the African Region [9], IMIA-LAC, the Latin American and Caribbean Federation for Health Informatics [10], and the North American Region. A Middle East Region is in the process of formation and is planned to become an official part of IMIA soon. Reports on these regional medical informatics organizations can be found in this IMIA Yearbook.

\section{Past Activities}

In many ways 2008 was a turning point for the IMIA family. Immediately after Medinfo 2007 we 'hit the ground running' in our efforts to assure our
IMIA community and the world that 'IMIA - Towards 2015' [11] was more than a paper-based strategic plan - that, indeed, it was and continues to be IMIA's guide to "provide leadership and expertise to the multidisciplinary health focused community and policy makers to enable the transformation of health care in accord with the world-wide vision to improve the health of the world population" [4]. We recognized that IMIA needed to change in order to continue to play its leading role in global biomedical and health informatics. Finding the right balance between continuity and transition was one of IMIA's challenges.

In this section I will mention just some of IMIA's major activities during the last year. Many other activities, as well as more details on the ones mentioned, are documented separately in this Yearbook, on IMIA's web page, and in IMIA's News, continuously published (and freely downloadable) in one of IMIA's official journals, Methods of Information in Medicine [12].

\subsection{IMIA General Assembly 2008 and MIE 2008}

In 2008, IMIA's General Assembly meeting was held on May 25 in Gothenburg, Sweden. Together with a Board Meeting the day before, it immediately preceded EFMI's 21 ${ }^{\text {st }}$ Medical Informatics Europe Congress, MIE 2008. With about 500 participants and a high-level scientific program, this congress has been a great success [13]. My congratulations go to EFMI's past and new presidents respectively, George Mihalas and Jacob

Table 1 IMIA members. The numbers are calculated at the end of the calendar year.

\begin{tabular}{|lccccc|}
\hline Members & 2008 & 2007 & 2006 & 2005 & 2004 \\
\hline Nations & 53 & 52 & 46 & 45 & 45 \\
Academic & 49 & 48 & 43 & 46 & 41 \\
Corporations & 11 & 12 & 10 & 10 & 10 \\
Corresponding & 33 & 33 & 31 & 29 & 19 \\
Total & 146 & 145 & 130 & 130 & 115 \\
\hline
\end{tabular}

Hofdijk, to the Scientific Program Committee, chaired by Stig Anderson, and to the Organizing Committee, chaired by Ragnar Nordberg.

During IMIA's General Assembly, some major decisions with implications for the future of IMIA were made. In particular, there was a vote in principle for a biennial Medinfo cycle, starting from Medinfo 2013, to replace the current triennial cycle for Medinfos. As our field is becoming more important, there was seen to be a need to re-evaluate and reshape the frequency of IMIA's international conferences. The need to be informed about and to discuss recent progress in our field has obviously increased within the past few years. The implications for all our major conferences and events is being discussed with our regional organizations, in order to ensure a timely and co-ordinated joint portfolio of international conferences where high-level, peer-reviewed results of health and biomedical informatics research and practice can be presented and discussed, independent of financial or political interests. A Biennial Medinfo Cycle Task Force, nominated by the General Assembly, is currently working out many of the other implications and details. These will be presented during IMIA's next General Assembly, which will be held in November 2009 in Hiroshima, Japan.

\section{$3.22^{\text {nd }}$ IMIA Board Meeting 2008 and InfoLAC 2008}

In October 2008, the IMIA Board met in parallel with the conferences organized by IMIA-LAC and the Argentine Association of Medical Informatics, as well as the meeting of IMIA's Working Group on Health and Biomedical Informatics Education, which took place in Buenos Aires and Pilar, Argentina.

The $3^{\text {rd }}$ Latin American and Caribbean Congress of Medical Informatics, InfoLAC 2008, attracted about 700 participants. InfoLAC, in my experience, was an event which took the con- 
cept of collaboration to exceptional new heights. InfoLAC was developed through the auspices of IMIA-LAC, AAIM (the Argentine Association of Medical Informatics), and the Austral University Hospital in Pilar. IMIA provided financial aid to offset travel and lodging costs of regional delegates, and, in order to demonstrate its unequivocal support, held its second Board meeting during the conference and convened meetings of several of its committees and task forces. My sincere congratulations go to Alvaro Margolis as President of IMIA-LAC, to InfoLAC's Honorary President Valerio Yácubsohn, to InfoLAC's President Juan Carlos Di Lucca, to Daniel Luna as chairman of the Scientific Program Committee and to the many other colleagues, who made InfoLAC 2008 such a success.

InfoLAC 2008 was preceded by 'Building Worldwide Capacity for the Health Informatics Workforce' - a major workshop held by the IMIA Health and Medical Informatics Education Working Group and hosted by the Hospital Italiano de Buenos Aires. The Working Group on Education meeting was excellently prepared by Bill Hersh as working group chair and Paula Otero as organising committee chair, together with many other colleagues. Among other activities, an advanced draft version of IMIA's revised recommendations on biomedical and health informatics education was presented and discussed. I very much look forward to the endorsement of the final document. In addition, the week of events included two days of pre-conference tutorials and the $2^{\text {nd }}$ Argentine Symposium of Nursing Informatics.

Alongside these two conferences, the IMIA Board and two IMIA committees met in Pilar. This was probably the latest time that a 'Spring Board Meeting' has been held in the history of IMIA. A first meeting of the Biennial Medinfo Cycle Task Force took place and was successful. As it became clear that such a change will have a significant impact on the structure of IMIA, and that there is a need to expand the current IMIA secretariat to become a more comprehensive IMIA office, the Board established a 'preparatory group for the IMIA Office' to work out details. Recommendations from this group will be presented during IMIA's next General Assembly in Hiroshima, Japan.

\subsection{Medinfo 2010}

The $13^{\text {th }}$ World Congress on Medical Informatics, Medinfo 2010, will be held from September 13 to 16, 2010 in Cape Town, South Africa. For the first time, a Medinfo congress will take place in Africa.

The planning for Medinfo 2010 has been intensified in 2008, and preparatory work is well under way. A web site has been set up [14]. The Scientific Program Committee (SPC) has been nominated, as have the Organizing Committee (OC) and the Editorial Committee (EC). The SPC is chaired by Riccardo Bellazzi and Johanna Westbrook, the OC by Lyn Hanmer, and the EC by Charles Safran.

In 2008 I had the personal pleasure of visiting the conference site of Medinfo 2010 in Cape Town. It is an excellent venue, located close to Cape Town's beautiful waterfront area.

\subsection{Implementing IMIA's Strategic Plan}

IMIA continued its efforts to the transition of the IMIA Strategic Plan [4, 15, 16]. The IMIA General Assembly established a new Vice-President position on Strategic Planning Implementation and Communication. Peter Murray has been elected to this position, and will continue his efforts for IMIA in this new role.

\subsection{IMIA, WHO and the 2008 Bellagio Conferences}

In 2007, WHO and IMIA announced their intention to intensify their collabo- ration [17]. One outcome of this closer collaboration was IMIA's participation at WHO's 'Global Observatory for eHealth Strategic Planning Workshop' in April 2008 in Bellagio, Italy. Major results have been summarized and published in [18].

IMIA is also continuing to make use of its facilitative role in bringing the wealth of knowledge embodied by the IMIA membership to bear on global issues. The most visible of these activities was our participation in the Rockefeller Foundation's month-long conference 'Making the eHealth Connection: Global Partnerships, Local Solutions', also held in Bellagio, in the summer of 2008 [19]. At that conference IMIA took its rightful place as one of 13 prestigious international organizations who acted as convenors of the conference.

\subsection{IMIA's Endorsement of STARE-HI}

Last, but not least, let me mention that a comprehensive list of principles, relevant for properly describing health informatics evaluations, had been jointly developed by the respective working groups of EFMI and IMIA. As result, a 'Statement on Reporting of Evaluation Studies in Health Informatics' (STARE-HI) is now available [20].

The objective of STARE-HI "is to provide guidelines for writing evaluation reports in Health Informatics which can be reliably interpreted by subsequent readers; and by doing this to improve the quality of published evaluation studies in Health Informatics" [20, p. 3]. IMIA's General Assembly 2008 endorsed this important document for our field. It has been published in the International Journal of Medical Informatics [20], the other one of the two official IMIA journals.

After the 'IMIA Code of Ethics for Health Information Professionals' and the 'IMIA Recommendations on Education in Health and Medical Informatics', STARE-HI has become the third endorsed document of IMIA. 
It is expected that STARE-HI will contribute to an increasing quality of evaluation studies in our field.

\section{Looking at the Develop- ment of Our Field Through the IMIA Yearbook}

As mentioned in my last report [2], the IMIA Yearbook's traditional best paper selection, together with invited survey and review papers, may be regarded as 'THE' global observatory for progress in health and biomedical informatics.

Starting in 1992 under the leadership of Jan H. van Bemmel and Alexa McCray, and now edited by Antoine Geissbuhler and Casimir Kulikowski, IMIA is proud to have such a comprehensive yearly periodical, not only documenting but also stimulating progress in our field. The Yearbook is one of IMIA's most visible and valuable 'products', not only to its members, but also to the health and biomedical community at large. Since 2006 the Yearbook is being published as a special issue of Methods of Information in Medicine. It is available as a printed volume and is also accessible online to a very broad audience of readers [4, 21, 22].

As I have done last year for 2007 [2], and in the year before for 2006 [1], let me for a third time reflect on the annual survey papers and selected best paper summaries of the recent IMIA Yearbook of Medical Informatics 2008 [23]. Again, from my point of view, we can observe progress in the various parts of our field, which in the Yearbook are published in seven 'regular' sections:

- Health and clinical management $[24,25]$ : The impact of information technology and information processing methodology is shown through studies, and patient safety is an important issue.

- Human factors [26, 27]. The former section of patient records (until 2001 computer-based patient records) has been renamed as human factors. This emphasises the growing priority within our field on user acceptance and usability. Surveying informatics aspects in order to support aging societies also highlights the importance of pervasive health care [28] as a new field.

- Health information systems [29, 30]: Monitoring the quality of institutional information systems and analysing the usability of open source products are major issues. The trend from institution-centered to patient-centered information processing [31] is continuing.

- Sensor, signal and imaging informatics [32, 33]: There is a broad variety of application fields with high clinical impact.

- Decision support, knowledge acquisition and management [34, 35]: Research on medical ontologies is focusing on knowledge access, but also increasingly on automated analyses.

- Education and consumer informatics [36, 37]: Priorities are on analysing the use of Internet and teleconsulting services as well as eLearning capabilities for global health care work force development.

- Bioinformatics [38, 39]: The transition from basic biological-centered research in bioinformatics towards clinical bioinformatics is still continuing. Under the term systems biology, formal approaches for better understanding biomedical phenomena are investigated. This is leading to a revival of formal methods in "computational biology".

In addition let me mention that the 2008 Yearbook's special theme on access to health information [40] also accentuates an important, continuously growing field of research and practice in biomedical and health informatics. Finally let me refer to the written version of the IMIA Award lecture in this Yearbook from Jan van Bemmel, the last recipient of IMIA's highest award [41]. A 'MUST' for reading!

\section{Future Activities of IMIA}

In 2009 and beyond IMIA will continue growing along the directions described above finding the right balance between continuity and transition. While IMIA's major future activities have already been mentioned in section 3 , there are additional meetings and related themes that must be listed.

\subsection{Major IMIA Meetings in 2009}

In 2009, several IMIA and IMIA-related meetings will take place. Let me mention some of the most important ones, and I again refer the reader to more information in other sections of this Yearbook, on IMIA's web page, and in the IMIA News in Methods.

- From April 16 to April 17, HELINA 2009 is the major African informatics event of the year, taking place in Abidjan, Ivory Coast.

- IMIA's 2009 Spring Board Meeting will be held in Dublin, Ireland, on April 25, preceded by other IMIA meetings and a conference of the Health Informatics Society of Ireland.

- Nursing Infomatics 2009, the triennial world congress of IMIA's Special Interest Group on Nursing Informatics, takes place in Helsinki, Finland, from June 28 to July 1. IMIA committees will meet there, too.

- The major European Medical Informatics event, organized by EFMI, will be the $22^{\text {nd }}$ Medical Informatics Europe Congress, MIE 2009, in Sarajevo, Bosnia and Herzegovina, from August 29 to September 2.

- From November 21 to 25, in Hiroshima, Japan, the 'Collaborative Meetings in Health Informatics' (CoMHI 2009) will form a series of major conferences in biomedical and health informatics. During CoMHI 2009 the IMIA General Assembly will hold its 2009 meeting, and other IMIA committees will meet there. 


\subsection{Revision of IMIA's Recommen- dations of Education}

Health and biomedical informatics education has existed now for more than 35 years (e.g. [42]) and is still expanding worldwide. As the international organization devoted to health and biomedical informatics, we have to continue to intensify our efforts on highlevel informatics education. IMIA's recommendations on education in health and medical informatics have been published in 2000 [43] and have been intensively used. Under the leadership of John Mantas, co-chair of IMIA's working group on education, the IMIA recommendations on education have been updated. It is expected that the revisions will be finalized soon.

5.3 Enabling and Stimulating Highquality Translational Communication, Research, Education, and Practice

Enabling and stimulating translational activities from research to the practice of health care has become of growing importance for our field. These activities will have to reach beyond our own field, in the integrative and bridging tradition of IMIA. Discussions as in [44] may show that our field has the potential to play a major role in translational medicine.

Therefore, as in the past, we have to stimulate interdisciplinarity (e.g. [45, 46]). We also have to stimulate the transfer of knowledge from theory to practice, and vice-versa. An international, peer-reviewed journal designed to cultivate broad readership across health care, in order to communicate on informatics topics of translational interest and on the application of informatics principals is, from my point of view, still missing. It has been suggested in [47] and [48] that such an applied informatics journal may appeal to practicing physicians, health care administrators and CIOs as well as medical informaticians and that in a globalizing world with eHealth initia- tives spanning across borders, such a journal should be an international effort. IMIA may be an appropriate organization to support or initiate such a journal. First steps in this direction have been made.

\section{Invitation to Join in IMIA's Global Efforts}

Again, I would like to remind you that IMIA, an umbrella association of associations, societies, institutions and corporations, in reality consists of individuals that represent those members. If not already involved, you are invited to join in IMIA's global efforts. We all play an important role in successfully contributing to the development of good health in our societies that can help to build a healthier world that is even more worth living in for all people.

\section{Tribute to IMIA's Deceased Ex- ecutive Director Steven Huesing}

Steven Huesing, Executive Director of IMIA since 1997, passed away in April 2009 after a long illness, in the face of which he valiantly continued his exceptional contributions to the management and progress of IMIA across all its wide range of activities during this past year. It was especially fortunate and fitting, that in 2008 he was awarded the prestigious Canadian Health Informatics Award (CHIA) for Lifetime Achievement, acknowledging his tireless work as a leader, a pioneer, and an ambassador in advancing the use of computers and information technology in health care for more than 40 years. On behalf of IMIA, I extend my most heartfelt condolences to his family and friends, and wish to express the deep sympathy and appreciation of all his friends within IMIA who have written to me so movingly of his great personal help and encouragement to them over the years, and his exceptional stewardship of IMIA and its affairs during the time we all had the privilege of working with him. We will all sorely miss him, and his name will enter the annals of IMIA for his untiring contributions in promoting and maintaining the international activities of our society through many leadership transitions and critical junctions during the evolution of our association over the past twelve years. His obituary in this issue of the Yearbook [49], with contributions from all the past (and the present) Presidents of IMIA with whom Steven worked, details Steven's outstanding personal qualities and his great professionalism in the service of IMIA [50].

\section{Acknowledgements}

As IMIA President, I have the duty and the privilege to work with the members of the IMIA family in leading our association through this important time of growth and maturation. It is a responsibility which you have entrusted to me - and an honour that I accepted with passion and enthusiasm. Many persons have contributed so much to IMIA,- it is hardly possible for me to mention them all -, and so also to health and health care in our societies. My respect and my acknowledgements are conveyed to all of them. I am particularly grateful to the IMIA Board and to the IMIA Regional leadership, who (individually and collectively) have been unstinting in their support and cooperation in these challenging times. They have once again demonstrated their personal excellence and commitment to IMIA.

\section{References}

1. Haux R. Preparing for change: Medical informatics international initiatives for health care and biomedical research. Comput Methods Programs Biomed 2007; 88: 191-6.

2. Haux R. Health care and informatics: on IMIA's opportunities and responsibilities in its 5 th decade. Yearb Med Inform 2008: 1-6.

3. Haux R, Howe J, Marschollek M, Plischke M, Wolf KH. Health-enabling technologies for pervasive health care: on services and ICT architecture paradigms. Inform Health Soc Care 2008; 33: 77-89.

4. http://www.IMIA.org. Last access February 1, 2009

5. http://www.WHO.int. Last access February 1, 2009.

6. http://www.who.int/about/regions/en/index.html. Last access February 1, 2009.

7. http://www.APAMI.org. Last access February 1, 2009.

8. http://www.EFMI.org. Last access February 1, 2009

9. http://www.IMIA.org - member page; regional members; HELINA. Last access February 1, 2009.

10. http://www.IMIA-LAC.net. Last access February 2, 2009.

11. Lorenzi NM. Towards IMIA 2015 - the IMIA strategic plan. Yearb Med Inform 2007:1-5. 
12. http://www.methods-online.com. Last access February $1,2009$.

13. Anderson SK, Klein GO, Schulz S, Aarts J, Mazzoleni MC, editors. eHealth Beyond the Horizon - Get IT There. Amsterdam: IOS Press; 2008

14. http://www.medinfo2010.org. Last access February 1, 2009.

15. Murray PJ. The IMIA strategic plan - towards IMIA 2015. Yearb Med Inform 2008: 7-15.

16. Murray P, Haux R, Lorenzi N. Let a thousand flowers bloom: transition towards implementation of the IMIA strategic plan. Methods Inf Med 2007; 46: 625-8.

17. Geissbuhler A, Haux R, Kwankam SY. Towards health for all: WHO and IMIA intensify collaboration. Joint Communiqué during Medinfo 2007 in Brisbane. Methods Inf Med 2007; 46: 503-5.

18. Kay M, Santos J. Report on the World Health Organization global observatory for eHealth strategic planning workshop, April 2008. Methods Inf Med 2008; 47: 381-7.

19. http://www.ehealth-connection.org. Last access February 1, 2009

20. Talmon J, Ammenwerth E, Brender J, de Keizer N, Nykänen P, Rigby M. STARE-HI - Statement on reporting of evaluation studies in health informatics. Int J Med Inform 2009; 78: 1-9.

21. http://www.schattauer.de/index.php?id=1384. Last access February 1, 2009.

22. http://www.IMIApubs.org. Last access February 1, 2009

23. Geissbuhler A, Kulikowski C, editors. IMIA Yearbook of Medical Informatics 2008. Stuttgart: Schattauer; 2008.

24. Marin HF, Carr R. Nursing care systems: enhancing care processes in practice and management. Yearb Med Inform 2008: 25-8.

25. Kubias D. Health and clinical management - from hospital to home patient care management. Findings from the Yearbook 2008 Section on Health and Clinical Management. Yearb Med Inform 2008: 29-32.

26. Demiris G, Hensel BK. Technologies for an aging society: a systematic review of "smart home" applications. Yearb Med Inform 2008: 33-40.

27. Ruch P. A bio-medical informatics perspective on human factors. Findings from the Yearbook 2008 Section on Human Factors. Yearb Med Inform 2008: 41-3.
28. Bardram JE. Pervasive healthcare as a scientific discipline. Methods Inf Med 2008; 47:178-85.

29. Murray PJ, Cabrer M, Hansen M, Paton C, Elkin PL, Erdley WS. Towards addressing the opportunities and challenges of Web 2.0 for health and informatics. Yearb Med Inform 2008: 44-51.

30. Bréant C. Health information systems: current challenges and developments. Findings from the Yearbook 2008 Section on Health Information Systems. Yearb Med Inform 2008: 52-4.

31. Kuhn KA, Giuse DA, Lapao L, Wurst SH. Expanding the scope of health information systems from hospitals to regional networks, to national infrastructures, and beyond. Methods Inf Med 2007; 46: $500-2$.

32. Müller H. Medical multimedia retrieval 2.0. Yearb Med Inform 2008:55-63.

33. Müller H. Sensors, signals, and images in medical informatics: progress and evaluation. Findings from the Yearbook 2008 Section on Sensors, Signals, and Imaging Informatics. Yearb Med Inform 2008: 64-6.

34. Bodenreider O. Biomedical ontologies in action: role in knowledge management, data integration and decision support. Yearb Med Inform 2008: 67-79.

35. Rassinoux AM. Decision support, knowledge representation and management: structuring knowledge for better access. Findings from the Yearbook 2008 Section on Decision Support, Knowledge Representation and Management. Yearb Med Inform 2008: 80-2.

36. Taylor L, Abbott PA, Hudson K. E-learning for health-care workforce development. Yearb Med Inform 2008: 83-7.

37. Boyer C. Education and consumer informatics: improvements in existing systems. Findings from the Yearbook 2008 Section on Education and Consumer Informatics. Yearb Med Inform 2008: 88-90.

38. Burgun A, Bodenreider O. Accessing and integrating data and knowledge for biomedical research. Yearb Med Inform 2008: 91-101.

39. Yip YL. The promise of systems biology in clinical applications. Findings from the Yearbook 2008 Section on Bioinformatics. Yearb Med Inform 2008: 102-4.

40. Geissbuhler A. Access to health information: a key for better health in the knowledge society. Yearb Med Inform 2008: 20-1.

41. van Bemmel JH. Reflections on curiosity. Yearb
Med Inform 2008: 183-8.

42. Knaup P, Haag M, Leven FJ, Dickhaus H. Challenges in the evolution of the medical informatics program at Heidelberg/Heilbronn. Methods Inf Med 2009 ;48: 66-75.

43. Recommendations of the International Medical Informatics Association (IMIA) on education in health and medical informatics. Methods Inf Med 2000; 39: 267-77.

44. Altman RB, Balling R, Brinkley JF, Coiera E, Consorti F, Dhansay MA, et al. Commentaries on "Informatics and medicine: from molecules to populations". Methods Inf Med 2008; 47: 296-317.

45. Winter A, Funkat G, Haeber A, Mauz-Koerholz C, Pommerening $\mathrm{K}$, Smers $\mathrm{S}$, et al. Integrated information systems for translational medicine. Methods Inf Med 2007; 46: 601-7.

46. Breu R, Sztipanovits J, Ammenwerth E. Modelbased design of trustworthy health information systems. Methods Inf Med 2008; 47: 389-91.

47. Lehmann CU, Altuwaijri MM, Li YC Ball MJ, Haux R. Translational research in medical informatics or from theory to practice. A call for an applied informatics journal. Methods Inf Med 2008; 47: 1-3.

48. Ball MJ, Silva JS, Bierstock S, Douglas JV, Norcio AF, Chakraborty J, et al. Failure to provide clinicians useful IT systems: opportunities to leapfrog current technologies. Methods Inf Med. 2008; 47: 4-7.

49. Geissbuhler A, Kulikowski C, editors. Yearb Med Inform 2009.

50. Geissbuhler A, Kulikowski C, editors. Yearb Med Inform 2009:17-22.

\section{Correspondence to}

Dr. Reinhold Haux

President, International Medical Informatics Association

Full Professor and Director

Peter L. Reichertz Institute for Medical Informatics

University of Braunschweig - Institute of Technology and

Hannover Medical School, Germany

Muehlenpfordtstr. 23

D-38106 Braunschweig, Germany

Tel: +49(0)531 3919501

Fax: +49(0)531 3919502

E-mail: Reinhold.Haux@plri.de

www.pli.de

IMIA Yearbook of Medical Informatics 2009 